\title{
Methodological Study of Government Resource Optimal Allocation and Control
}

\author{
Qin Liao Jiabi Zheng Zhonghua Tang \\ School of Mathematical Sciences, South China University of Technology, Guangzhou 510640, P.R. China
}

\begin{abstract}
It's a hot research issue to integrate information technology into the Government Resource Planning (GRP). The indices of current GRP system are just with expression of "investment" form which is disconnected with "output" form for control indices and "result" form for evaluation indices. Thus the current GRP system model failed in supervising resource usage and getting in-time feedback. This article focuses on solving consistency of the indices of the GRP processes, designing the approaches of indices transformation and establishing a uniform foundational index system that provides theoretical basis for the implementation of maximal efficiency and effect of government resource management.
\end{abstract}

Keywords: Government resource allocation, Control and evaluation, Output index system, Interval genetic algorithm

\section{Introduction}

Government Resource Planning (GRP) is based on the optimization management of ERP, using modern information techniques, allocate the resources reasonably and improve the government's functions of economic regulation, market supervision, social management and public service, thus improve the efficiency and effect. As an administrative body, government holds extensive resources such as Human Resources, Material Resources, Financial Resources, Security Resources and Information Resources. These resources are allocated to all areas at all levels through various government departments as the basic distribution channels so as to support social services and construction of the government. The current GRP model regards the planning of government resource as the core function and focuses on scientific and rational allocation of resources. The resource forecast and allocation is with expression of "investment" form which can't be directly used for the resource control and evaluation. The functional departments have to establish new control and evaluation index systems which are seldom inherent connection with the planning indices, thus leads to the situation that the control and evaluation are inconsistency with the planning. This also limits the possibility of the adaptive feedback and the lack of restriction during the execution of GRP. Aiming at establishing the uniform index system for planning, control and evaluation, this article studies the feasible methods for the transformation from the "investment" form for planning to the "output" form for control and the "result" form for evaluation. Moreover, an effective adaptive monitor and feedback model is designed to achieve the government's maximum efficiency and effect through the resources planning, control and evaluation.

\section{Establishment of GRP investment index system}

Taking the existing GRP system as a reference, considering different allocation patterns of our country and abroad, we established a tree-structure resources planning system with 3 layers which can reflect the resource type and flowing trait clearly. The resource type, functional department and the concrete government project are corresponding to the 3 layers through which the resources are distributed and thus form the resource planning which is with expression of "investment" form. The first so-call resource layer includes Material Resource, Human Resource, Financial Resource, Security Resource and Information Resource; the second layer is the functional department layer which can be categorized into 13 parts which are Ministry of Land and Resource, Ministry of Construction, Ministry of Agriculture and Forestry, Ministry of Transportation, Ministry of Public Health and Education, Ministry of Labor Insurance and Civil Administration, Ministry of Economy and Trade, Ministry of Finance, Ministry of Justice , Ministry of National Security, Other ministries, Ministry of Science Technology and Government Office. These 13 parts are subjected to the resource type. The last layer is the government project including Expenditure for capital construction, Urban maintenance Expenditure and Expenditure for operating expenses of education etc. There are totally 30 indices in this layer and Table 1 shows the structure of the three layers that focuses on the Material Resource. 


\begin{tabular}{|c|c|c|c|c|}
\hline The first layer & \multicolumn{4}{|c|}{ Material Resource } \\
\hline The second layer & $\begin{array}{c}\text { Ministry of } \\
\text { Land and Resource }\end{array}$ & $\begin{array}{l}\text { Ministry of } \\
\text { Construction }\end{array}$ & $\begin{array}{l}\text { Ministry of } \\
\text { Transportation }\end{array}$ & $\begin{array}{c}\text { Ministry of Agriculture and } \\
\text { Forestry }\end{array}$ \\
\hline \multirow{3}{*}{ The third layer } & $\begin{array}{l}\text { Expenditure for Land } \\
\text { and Sea Area } \\
\text { Development and } \\
\text { Construction }\end{array}$ & $\begin{array}{l}\text { Expenditure for } \\
\text { Capital } \\
\text { Construction }\end{array}$ & $\begin{array}{l}\text { Operating Expenses of } \\
\text { Department of } \\
\text { Transportation }\end{array}$ & $\begin{array}{l}\text { Expenditure for Supporting } \\
\text { Agricultural Production }\end{array}$ \\
\hline & $\begin{array}{l}\text { Geological } \\
\text { Prospecting } \\
\text { Expenses }\end{array}$ & $\begin{array}{c}\text { Urban } \\
\text { Maintenance } \\
\text { Expenditure }\end{array}$ & & $\begin{array}{l}\text { Expenditure for Agriculture } \\
\text { Comprensive Development }\end{array}$ \\
\hline & & & & $\begin{array}{c}\text { Expenditure for Agriculture, } \\
\text { Forestry, Irrigation and } \\
\text { Meteorology }\end{array}$ \\
\hline
\end{tabular}

Table 1: The structure of 3-layer resource planning indices focuses on Material Resource.

The resource planning should consider both the former level and the variation in the future. Therefore, the predictions of planning data are calculated according to the historic data on one hand, and are revised with respect to the government plan, policy and economical environment on the other hand. Let $D_{i}$ be the $i^{\text {th }}$ ministry with indices $x_{i k}(k=1,2 \ldots P)$ referring to the government project subjected to this ministry. If the former $j$ years' investments of these $P$ indices are $x_{i k}^{(j)}$, we have

$$
D_{i}^{(j)}=x_{i 1}^{(j)}+x_{i 2}^{(j)} \cdots x_{i p}^{(j)}, j=1,2 \ldots m .
$$

Suppose $x_{i k} / D_{i}=\beta_{i k}$, then $x_{i k}=D_{i} \beta_{i k}$, to compute $\beta_{i k}$ with Least Squares method, let

$$
Y_{i}=\sum_{j=1}^{m} \alpha_{j}\left(x_{i k}^{(j)}-D_{i k}^{(j)} \beta_{i k}\right)^{2}
$$

where, $\alpha_{k}$ are weights of years.

$$
\begin{aligned}
& \frac{d Y_{i}}{d \beta_{i k}}=-2 \sum_{j=1}^{m} \alpha_{j}\left(x_{i k}^{(j)}-D_{i}^{(j)} \beta_{i k}\right) D_{i}^{(j)}=0 \\
& \beta_{i k}=\sum_{j=1}^{m} \alpha_{j} x_{i k}^{(j)} D_{i}^{(j)} / \sum_{j=1}^{m} \alpha_{j}\left(D_{i}^{(j)}\right)^{2}
\end{aligned}
$$

Define $\gamma_{i k} \quad\left(\gamma_{i k}>0\right)$ is the support development intensity of indices $X_{i k}$ under the effect of policy, let

$$
\hat{\beta}_{i k}=\gamma_{i k} \beta_{i k} / \sum_{k=1}^{P} \gamma_{i k} \beta_{i k}
$$

we can get the investment proportions $\hat{\beta}_{i k}$ of all $x_{i k}$ which are subjected to investment indices $D_{i}$. Therefore, based on the historical data of former $j$ years and the relationship of each index which is similar to tree-node, we can predict the resource investment proportions of each layer's indices by the proportion coefficients from the top down or from the bottom up, and then form resource planning of all levels. Considering the data from 1993 to 2005 in Statistical Yearbook as correlative data we need, we can get the prediction values of resource planning in the form of investment, and Table 2 shows the prediction values of Ministry of Construction.

\begin{tabular}{|l|l|l|l|}
\hline & $\begin{array}{l}\text { The second } \\
\text { layer }\end{array}$ & \multicolumn{2}{|l|}{ The third layer } \\
\cline { 2 - 4 } & $\begin{array}{l}\text { Ministor of } \\
\text { Construction }\end{array}$ & $\begin{array}{l}\text { Expenditure } \\
\text { for Capital } \\
\text { Construction }\end{array}$ & $\begin{array}{l}\text { Urban } \\
\text { Maintenance } \\
\text { Expenditure }\end{array}$ \\
\hline $\begin{array}{l}\text { Prediction } \\
\text { values }\end{array}$ & $333.97-$ & $252.63-$ & $81.70-94.71$ \\
\hline $\begin{array}{l}\text { Actual } \\
\text { values }\end{array}$ & 352.17 & 265.64 & 86.1 \\
\hline
\end{tabular}

Table 2: Comparing prediction values with actual values of resource planning (unit: 10000 Yuan)

\section{Establishment of government resource output planning index system}

To establish organic link between Government resource planning and control, and to make the control \& evaluation of resource usage effective, the "investment" index of GRP should be transformed to "output” index which can be controlled directly, that is, we can estimate the benefit of economy and society given the definite resource planning scheme, and express them as quantificational indices, then form output planning by output indices, after that, the control of "investment" planning is transformed to control of 
“output” planning. Output planning can be taken as a reference of efficiency \& effect of resource usage, according to this reference, we adjust and optimize the resource usage, and we can not only manage and control resource, but also analyze and evaluate the efficiency of the resource usage.

\subsection{Establishment of resource output index system}

In order to choose some output planning indices which are correlative with resource planning closely, we choose output indices by screening out the indices which are correlative with benefit of economy and society closely on the basis of existing knowledge. Because the indices subjected to the same function department in the resource planning system should present correlative in a certain extent, we categorize those indices into different function departments. Then according to the representative, homogeneity, mensurability, we select the output planning indices from the index clusters of each function department. In this paper, we choose 54 output indices which are corresponding to different departments respectively in resource planning system. Table 3 shows the third layer planning indices and the corresponding output indices which focuses on Ministry of Construction.

\begin{tabular}{|c|c|c|}
\hline \multicolumn{2}{|c|}{ Resource planning indices } & Output indices \\
\hline The second layer & The third layer & \\
\hline & & Percentage of Urban Population with Access to Tap Water \\
& Expenditure for Capital & Per Capita Area of Paved Roads (sq.m) \\
Ministry of & Construction & Percentage of Urban Population with Access to Gas \\
Construction & Per Capita Public Green Land (sq.m) \\
& Urban Maintenance & Number of Latrines Per 10 000 Persons (unit) \\
& Expenditure & Per Capita Floor Space of Residents (sq.m) \\
& Rate of Capital Fixed Assets Put into Use \\
& Rate of Capital Construction Projects Completed and Put into Use \\
\hline
\end{tabular}

Table 3: Corresponding relationships between resource planning indices and output planning indices.

\subsection{Confirmation of the values of resource output indices}

After establishing output index system, we can confirm the values of output indices by the corresponding values of resource planning indices. One investment index is probably corresponding to several output indices in resource planning, therefore, the key to transformation of index system is to establish quantitative relationship which is many-to-many and different dimensions between $t$ investment indices and $n$ output indices. It is difficult to actualize with normal math model when $\mathrm{t}<\mathrm{n}$, consequently, this paper proposes a new method, namely, multi-object interval genetic algorithm (GA) to confirm output planning through resource planning.

We transform the question that confirms the values of output indices by the values of investment indices to the question that reflects the values of investment indices by the values of output indices. In this paper, object variables $Y_{1}, Y_{2}, \cdots Y_{n}$ are resource planning indices; independent variables $x_{1}, x_{2}, \cdots x_{n}$ are predictions of variation value of output planning indices. Based on the historical resource planning schemes and relevant data of output indices, we can fit the function with BP neural network (NN) as follows:

$$
\begin{gathered}
Y_{i}=F_{i}\left(x_{1}, x_{2}, \cdots, x_{n}\right)=f\left(\sum_{q=1}^{M} V_{i q} f\left(\sum_{j=1}^{n} w_{q j} x_{j}-\theta_{q}\right)-r_{i}\right) \\
Y_{i-\min } \leq Y_{i} \leq Y_{i-\max } a_{j} \leq x_{j} \leq b_{j} \\
i=1,2, \cdots t, j=1,2, \cdots n
\end{gathered}
$$

where, $F_{i}$ is BP NN model, $V_{i q}$ are link weights between output nodes and hidden nodes, $w_{q j}$ are link weights between hidden nodes and input nodes, $\theta_{q}, r_{i}$ are thresholds, $f$ is $S$ function.

If investment indices $Y_{1}, Y_{2}, \cdots Y_{t}$ are definite, we can obtain the optimal values of output indices $x_{1}, x_{2}, \cdots x_{n}$ with multi-object interval GA which contains two steps. The first step is to express $n$ output indices as solution $\mathrm{X}=\left(x_{1}, x_{2}, \cdots x_{n}\right)$ in which $\mathrm{X}$ is corresponding to a chromosome and each output index stands for gene. For each output index, produce gene $x_{i}^{(k)}$ randomly among their definitional domains, and form $\mathrm{N}$ chromosomes $X^{(k)}=\left\{x_{1}^{(k)}, x_{2}^{(k)}, \cdots, x_{n}^{(k)}\right\}$, $(k=1,2, \cdots N)$ which mean $\mathrm{N}$ different output planning schemes. The corresponding resource planning of population $S=\left\{X^{(1)}, X^{(2)}, \cdots, X^{(N)}\right\}$ is: 


$$
\left\{Y^{(1)}, Y^{(2)}, \cdots ; Y^{(N)}\right\}=\left\{\left(Y_{1}^{(1)}, \cdots ; Y_{t}^{(1)}\right), \cdots\left(Y_{1}^{(N)}, \cdots ; Y_{t}^{(N)}\right)\right\}
$$

Let $\left[Y_{i-\min }, Y_{i-\max }\right]$ be the ranges of the values of indices $Y_{i}$ in definite resource planning, midpoint $Y_{i-\text { mid }}$ be $\left(Y_{i-\min }+Y_{i-\max }\right) / 2$, define the fitness function as:

$$
F\left(X^{(k)}\right)=\frac{1}{\sum_{i=1}^{t}\left(Y_{i}^{(k)}-Y_{i-m i d}\right)^{2}+\alpha}+\sum_{i=1}^{t} \beta \operatorname{sgn}\left(D_{i}\right)
$$

where, $D_{i}=\frac{Y_{i-\max }-Y_{i-\min }}{2}-\left|Y_{i}^{(k)}-Y_{i-\text { mid }}\right|$ and when

$D_{i}>0, \operatorname{sgn}\left(D_{i}\right)=1$, when $D_{i} \leq 0, \operatorname{sgn}\left(D_{i}\right)=0$, $\beta$ is regulative coefficient. We can obtain the output planning scheme $X_{0}=\left(x_{1}^{(0)}, x_{2}^{(0)}, \cdots x_{n}^{(0)}\right)$ with GA when the value of fitness is maximal, that is, the output planning is proximal with the midpoint $\left(Y_{1-\text { mid }}, Y_{2-\text { mid }}, \cdots Y_{t-\text { mid }}\right)$ of definite output planning indices $Y_{1}, Y_{2}, \cdots Y_{t}$.

Generally, it is unpractical to make the values of the output indices be certain in the control process of the resource usage, therefore, the second step of interval GA is to give the alterable ranges of output planning so as to the corresponding resource planning indices won't deflect anticipant ranges of definite resource planning when the values of output indices are among the alterable ranges. On the basis of optimal output index $\quad X_{0}=\left(x_{1}^{(0)}, x_{2}^{(0)}, \cdots x_{n}^{(0)}\right)$, let $C_{i}=\max _{1 \leq k \leq N}\left\{x_{i}^{(k)}\right\}-\min _{1 \leq k \leq N}\left\{x_{i}^{(k)}\right\} \quad$, produce positive numbers $\quad \varepsilon_{i} \quad, \quad \varepsilon_{i}=\min \left\{b_{i}-x_{i}^{(0)}, x_{i}^{(0)}-a_{i}, C_{i}\right\} \quad$, $i=1,2, \cdots n$, and extend each output index $x_{i}$ of optimal solution to be range $\left(x_{i}^{(0)}-\varepsilon_{i}, x_{i}^{(0)}+\varepsilon_{i}\right)$ whose midpoint is fixed, produce $M$ new chromosomes
$X^{(k)}=\left(x_{1}^{(k)}, x_{2}^{(k)}, \cdots x_{n}^{(k)}\right)$ randomly among the certain ranges, $\quad$ where, $\quad k=1,2, \cdots, M$, $x_{i}^{(k)} \in\left(x_{i}^{(0)}-\varepsilon_{i}, x_{i}^{(0)}+\varepsilon_{i}\right) \quad, \quad$ define new population $S^{\prime}=\left\{X^{(0)}, X^{(1)}, \cdots X^{(M)}\right\}$, and use the fitness $F\left(X^{(k)}\right)$ used at the first step, repeat GA for $\mathrm{M}+1$ chromosomes, then we can get new chromosomes which satisfy:

$\left|Y_{i}^{(k)}-Y_{i-\text { mid }}\right|<\frac{Y_{i-\max }-Y_{i-\min }}{2},(i=1,2, \cdots, t)$

Choose $w$ chromosomes whose values of fitness are maximal, and sort ascending the $i^{\text {th }}$ gene of $w$ chromosomes as $\tilde{x}_{i}^{w_{1}}, \tilde{x}_{i}^{w_{2}}, \cdots \tilde{x}_{i}^{w_{w}}$, then the mutative ranges of the corresponding output indices are $\left[\tilde{x}_{i}^{w_{1}}, \tilde{x}_{i}^{w_{w}}\right], i=1,2, \cdots, n$.

We can test the probability of investment indices among the planning ranges when the corresponding output indices are among the control ranges $\left[\tilde{x}_{i}^{w_{1}}, \tilde{x}_{i}^{w_{w}}\right]$ by statistical trials, that is, do random trial $\mathrm{H}$ times, produce random variables $x_{i}$ among the mutative ranges of each output index, then form $\mathrm{H}$ output indices and the output planning scheme, and judge how many $Y^{(j)}$ existing which make $Y_{i}^{(j)}$ satisfy determinate resource planning scheme, namely, $Y_{i-\min } \leq Y_{i}^{(j)} \leq Y_{i-\max }$, then we confirm the approximate probability of output indices which are coherent with investment indices when they are among the control ranges.

Take the planning indices of Ministry of Construction in 2003 and in Table 3 for example. The two 3-level indices $\left(Y_{1}, Y_{2}\right)$ can be transformed to eight indices of output planning $x_{1}, x_{2}, \cdots x_{8}$ by interval genetic algorithm. And the values of output indices are shown in Table 4.

\begin{tabular}{|c|c|c|c|}
\hline Output indices & $\begin{array}{c}\text { Values of output planning in } \\
2004\end{array}$ & $\begin{array}{c}\text { Actual values of } \\
\text { output indices in } \\
2003\end{array}$ & $\begin{array}{c}\text { Actual values of } \\
\text { output indices in } \\
2004\end{array}$ \\
\hline $\begin{array}{c}\text { Percentage of Urban Population with Access } \\
\text { to Tap Water }\end{array}$ & $87.41-88.96$ & 86.2 & $\mathbf{8 8 . 9}$ \\
\hline Per Capita Area of Paved Roads (sq.m) & $10.57-11.24$ & 9.3 & 10.3 \\
\hline $\begin{array}{c}\text { Percentage of Urban Population with Access } \\
\text { to Gas }\end{array}$ & $78.54-85.03$ & 76.7 & $\mathbf{8 1 . 5}$ \\
\hline Per Capita Public Green Land (sq.m) & $6.94-7.97$ & 6.5 & $\mathbf{7 . 4 6}$ \\
\hline Number of Latrines Per 10 000 Persons (unit) & $3.53-3.64$ & 3.2 & 3.2 \\
\hline Per Capita Floor Space of Residents (sq.m) & $23.96-24.53$ & 23.67 & $\mathbf{2 4 . 9 7}$ \\
\hline Rate of Capital Fixed Assets Put into Use & $57.34-60.40$ & 62.6 & $\mathbf{5 8 . 9}$ \\
\hline $\begin{array}{c}\text { Rate of Capital Construction Project Cost Put } \\
\text { into Production }\end{array}$ & $51.49-52.65$ & 53.2 & $\mathbf{5 2 . 5}$ \\
\hline
\end{tabular}

Table 4: Comparing the output planning in 2005 with actual values of output indices in 2004 and 2005. 
Comparing the values of output planning in 2004 with the actual values of output indices in 2003, we discover that the values of output planning set a new aim for output indices on the basis of actual values in2003, which is quantitative aim for the effect of resource usage. Contrasted the values of output planning to actual values in2004, five indices achieve the aim of output planning, one index excess output planning and two do not satisfy the basic demand.

\section{Establishment of GRP evaluation index system}

Because of the establishment of output index system, it is possible to have uniform index system for resource planning, control and evaluation. The aim of control and evaluation is to make the effect of resource usage be accordant with resource planning. Therefore, it is necessary to convert the "output" form to appraisable "result" form after the "investment" form of resource planning is transformed to controllable "output" form.

In this paper, "result" form is evaluated by effect and efficiency. Effect evaluation is the measurement of value relationship between resource output and resource investment; efficiency evaluation is the ratio measurement of actual output to intending output of resource usage.

\subsection{Effect evaluation of resource usage}

In 3.2, we established the quantitative relationship between output indices and resource planning indices with BP NN and one way to value the output indices is to introduce actual values $\bar{x}_{1}, \bar{x}_{2}, \cdots, \bar{x}_{n}$ of them to (6), then

$$
\begin{aligned}
& Y=\left(Y_{1}, Y_{2}, \cdots, Y_{t}\right)=\left(F_{1}\left(\bar{x}_{1}, \bar{x}_{2}, \cdots, \bar{x}_{n}\right), \cdots\right. \\
& \qquad \begin{array}{cr}
\left.F_{t}\left(\bar{x}_{1}, \bar{x}_{2}, \cdots, \bar{x}_{n}\right)\right) \\
\text { We } \\
\text { can }
\end{array} \\
& \begin{array}{lcr}
Y=\left(Y_{1}, Y_{2}, \cdots Y_{t}\right) & \text { calculate } \\
Y=\left(Y_{1}, Y_{2}, \cdots Y_{t}\right) & \text { with } & \text { actual }
\end{array}
\end{aligned}
$$

values $Y=\left(\bar{Y}_{1}, \bar{Y}_{2}, \cdots \bar{Y}_{t}\right)$, we can gain a difference which is set as effect evaluation basis of resource usage. The effect evaluations of department $D_{i}$ and comprehensive utilization of government resource can be expressed as (11) and (12) respectively.

$$
\begin{aligned}
& E f t_{D_{i}}=\sum_{j \in D_{i}} w_{i j}\left(Y_{j} / \bar{Y}_{j}\right), \sum_{j \in D_{i}} w_{i j}=1 \\
& E f t=\sum_{i} w_{i} E f t_{D_{i}}, \sum_{i} w_{i}=1
\end{aligned}
$$

where, $w_{i j}$ are weights of effect evaluations of all resource investment which are subjected to department $i, w_{i}$ are weights of effect evaluations of different departments in comprehensive effect evaluation. If $Y_{j} / \bar{Y}_{j}>1$, it shows the value of intending investment is bigger than actual investment, namely, the actual effect is better than expectation, or the actual effect is worse than expectation.

\subsection{Efficiency evaluation of resource usage}

If the actual values and intending values of output indices in certain year are $\bar{x}_{1}, \bar{x}_{2}, \cdots, \bar{x}_{n}$ and $x_{1}, x_{2}, \cdots x_{n}$ respectively, then the efficiency evaluations of departments and comprehensive utilization of government resource can be expressed as (13) and (14) respectively.

$$
\begin{aligned}
& E f y_{D_{i}}=\sum_{j \in D_{i}} v_{i j}\left(\bar{x}_{j} / x_{j}\right), \sum_{j \in D_{i}} v_{i j}=1 \\
& E f t=\sum_{i} v_{i}\left[E f y_{D_{i}}, \sum_{i} v_{i}=1\right.
\end{aligned}
$$

Similarly, $v_{i j}$ are weights of efficiency evaluations of each resource investment which are subjected to department $i, v_{i}$ are weights of efficiency evaluations of different departments in comprehensive efficiency evaluation. If $\bar{x}_{j} / x_{j}>1$, it shows the actual values of output indices are bigger than intending values, namely, the actual efficiency is better than expectation, or the actual efficiency is worse than expectation.

As shown in Table 4, computing the difference between the actual values of output indices in 2004 and 2005, using the result in (10), we can get: $Y=\left(Y_{1}, Y_{2}\right)=(248.48,85.72)$, as shown in Table 3 , the values of the third layer's indices are $Y=\left(\bar{Y}_{1}, \bar{Y}_{2}\right)=(254.13,86.1)$, the weights of effect evaluations can be obtained with hiberarchy analysis method and the values of them are $w_{21}=74.74, w_{22}=25.26$, the effect evaluations of department is $E f t_{D_{2}}=0.9823$;According to the variety of actual values of output indices and the values of output planning indices in Table 4 , after gaining the weights of efficiency evaluations $v_{2 j}$, we can get the efficiency evaluations of departments $E f y_{D_{2}}=1.054$ through formula (13).If the effect evaluations is less 
than 1, it indicates that the resource usage doesn't achieve merited effect; if the efficiency evaluation is bigger than 1, it indicates that realization of output planning is ideal. And when both of effect evaluation and efficiency evaluation don't achieve basic demand, we should analyze the reasons, and then judge that caused by warp which produced by control of resource usage or irrationality of resource planning, if caused by the first reason, we should adjust the parameters of monitoring intensity of control of resource usage, otherwise, we should feed back the difference to prediction model of resource planning then to modify parameters of resource planning which belong to corresponding departments so as to make the resource planning is more reasonable in next year.

\section{Optimal control and uniform index system for government resource planning, control and evaluation}

Fig.1 shows the uniform structure for resource planning, control and evaluation of resource usage of GRP.

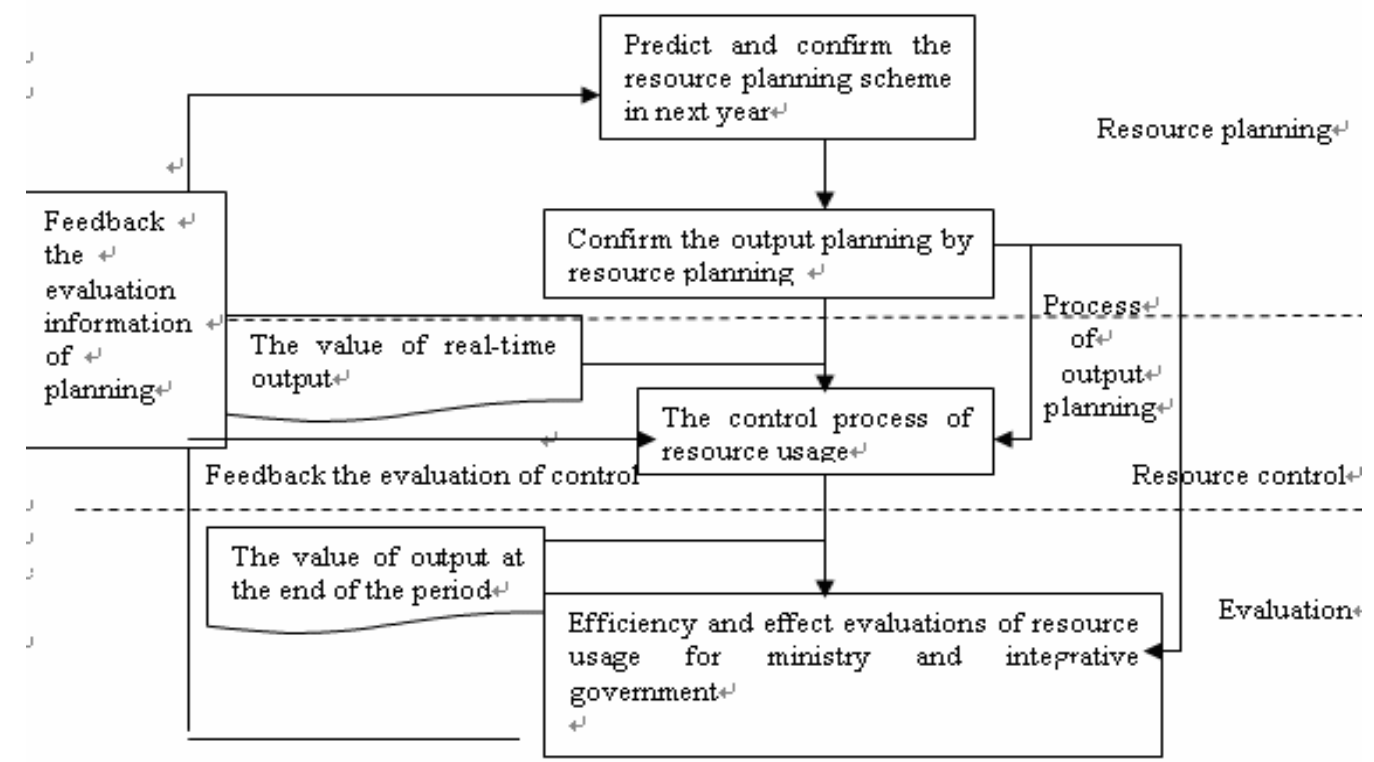

Fig. 1: Adaptive monitor system of GRP.

1. Resource planning: Confirming the investment proportion of all levels' indices of the resource allocation in next period based on the prediction model of resource planning which established with historical data, and integrating the development intensity defined by government, we can form the resource planning. Then confirm corresponding output planning of resource usage through the corresponding relationship between many investment indices and many output indices so as to the values of output indices can be considered as a reference of control and evaluation.

2. Control of resource usage: Transforming the output planning to periodic output planning with function interpolation method, and comparing real-time output indices of each period with periodic output planning indices, when the difference between them reaches stated extent, we give alarm and referenced control measure so as to keep the real-time output indices accordant with planning indices.
3. Evaluation of resource usage: Evaluating the efficiency and effect of resource usage through the actual and intending output at the end of the period. And, integrating the information of resource usage and resource planning, we evaluate the annual rationality of the resource planning of that year and feed back the information to the model of resource planning to adjust it; Moreover, integrating the warp extent and time extent between real-time output indices and periodic output planning indices, we evaluate the resource control and feed back the evaluation information so as to modify the alarm parameter of resource control.

The aforementioned monitor system makes the processes of GRP, namely, planning, control and evaluation, can run with uniform index system, in addition, it can adjust each tache of the model through the evaluation and feedback mechanism so as to the GRP system is more effective. 
Controlling and evaluating the resource planning \& resource usage of Ministry of Construction in 2004 with the adaptive monitor system of GRP mentioned above, we list the result in Table 5 . We give the resource planning scheme (the resource planning line in
Table 5 ), and transform it to output planning (the output planning line in Table 5), compute the effective and efficiency evaluation of resource usage (the evaluation of resource usage line in Table 5).

\begin{tabular}{|c|c|c|c|}
\hline \multicolumn{2}{|c|}{ Resource planning } & Output planning & $\begin{array}{l}\text { Evaluation of } \\
\text { resource usage }\end{array}$ \\
\hline \multirow{8}{*}{$\begin{array}{l}\text { Ministry of } \\
\text { Construction }\end{array}$} & \multirow{4}{*}{$\begin{array}{c}\text { Expenditure for } \\
\text { Capital } \\
\text { Construction } \\
\text { 252.63-265.64 } \\
\text { (Actual value: } \\
\text { 254.13) } \\
\text { (Unit:10000 yuan) }\end{array}$} & $\begin{array}{c}\text { Percentage of Urban Population with Access to Tap Water（\%） } \\
87.41-88.96\end{array}$ & \multirow{4}{*}{$\begin{array}{l}\text { Effect evaluation } \\
0.9823\end{array}$} \\
\hline & & $\begin{array}{c}\text { Per Capita Area of Paved Roads（sq.m.） } \\
10.57-11.24 \\
\end{array}$ & \\
\hline & & $\begin{array}{l}\text { Percentage of Urban Population with Access to Gas (\%) 78.54- } \\
85.03\end{array}$ & \\
\hline & & $\begin{array}{c}\text { Per Capita Public Green Land (sq.m) } \\
6.94-7.97\end{array}$ & \\
\hline & \multirow{4}{*}{$\begin{array}{c}\text { Urban Maintenance } \\
\text { Expenditure } \\
81.70-94.71 \\
\text { (Actual value:86.1) } \\
\text { (Unit:10000 yuan) }\end{array}$} & $\begin{array}{c}\text { Number of Latrines Per } 10000 \text { Persons (unit) } \\
3.53-3.64\end{array}$ & \multirow{4}{*}{$\begin{array}{c}\text { Efficincy } \\
\text { evalustion } \\
1.054\end{array}$} \\
\hline & & Per Capita Floor Space of Residents (sq.m) 23.96-24.53 & \\
\hline & & $\begin{array}{l}\text { Rate of Fixed Assets Put into Use（\%） } \\
57.34-60.40\end{array}$ & \\
\hline & & $\begin{array}{c}\text { Rate of Capital Construction Project Cost Put into Production } \\
\left(\begin{array}{c}\text { (\%) } \\
51.49-52.65\end{array}\right.\end{array}$ & \\
\hline
\end{tabular}

\section{Conclusions}

This paper proposes a tree-structure GRP system, and designs innovative Government resource output planning in the model of GRP. It establishes optimal structure of the relationship between $t$ investment indices and $n$ output indices with interval genetic algorithm, establishes quantitative and corresponding relationship between resource planning and output planning so as to the planning indices in the form of investment can be transformed to output indices that can be controlled directly, in addition, it also defines the effect and efficiency evaluation which based on output and values of it, so it makes up the disfigurements of current GRP which are weak contact, loose structure and different criterion and provides theoretical basis for realizing efficiency holistic mechanism, adaptive monitor, feedback and evaluation of GRP.

\section{Acknowledgement}

This research is supported by Soft Science Foundation of Guangdong Province (Grant No.4050290); Soft Science Foundation of Guangzhou (Grant No. B13N506013).

\section{References:}

[1] I. Sanderson, Performance Management, Evaluation and Learning in Modern Local
Government. Public Administration, 79(2): 297313, 2001.

[2] D.F. Kettl, Putting Performance Management to Work in the Federal Government. Paper of the 2001 Annual Meeting of the American Political Science, 2001.

[3] C. Coglianese, Jennifer Nash, Todd Olmstead, Performance-Based Regulation: Prospects and Limitations in Health, Safety, and Environmental Protection. Administrative law Review, 55(4): 705-730, 2003.

[4] Q. Alam, J. Pacher, Impart of Compulsory Competitive Tendering On the Structure and Performance of Local Government Systems in the State of Victoria. Public Administration and Development, 20(5): 359-371, 2000.

[5] M.Z. Zhang, etc., The analysis of innovation of American Federal Government. Chinese Public Administration, 6: 42-45, 1999.

[6] R.W. Tang, T.W. Tang, The Measurement of Provincial Governments' Efficiency of China in 2002. Chinese Public Administration, 6, 2004. 